\title{
Telemental Health For Youth With Chronic IIInesses: Systematic Review
}

Nancy Lau ${ }^{1,2,3}$, PhD; Susannah F Colt ${ }^{4}$, MA; Shayna Waldbaum ${ }^{5}$, BSc; Alison O'Daffer ${ }^{1}$, BA; Kaitlyn Fladeboe ${ }^{1,3,6}$, $\mathrm{PhD}$; Joyce P Yi-Frazier ${ }^{1}$, PhD; Elizabeth McCauley ${ }^{2,7}, \mathrm{PhD}$; Abby R Rosenberg ${ }^{1,3,6}$, MA, MSc, MD

${ }^{1}$ Palliative Care and Resilience Lab, Center for Clinical and Translational Research, Seattle Children's Research Institute, Seattle, WA, United States

${ }^{2}$ Department of Psychiatry and Behavioral Sciences, University of Washington School of Medicine, Seattle, WA, United States

${ }^{3}$ Cambia Palliative Care Center of Excellence, University of Washington, Seattle, WA, United States

${ }^{4}$ Perelman School of Medicine, University of Pennsylvania, Philadelphia, PA, United States

${ }^{5}$ Chicago Medical School, Rosalind Franklin University of Medicine and Science, North Chicago, IL, United States

${ }^{6}$ Department of Pediatrics, University of Washington School of Medicine, Seattle, WA, United States

${ }^{7}$ Center for Child Health, Behavior, and Development, Seattle Children's Research Institute, Seattle, WA, United States

\section{Corresponding Author:}

Nancy Lau, PhD

Palliative Care and Resilience Lab

Center for Clinical and Translational Research

Seattle Children's Research Institute

1920 Terry Ave

Seattle, WA, 98101

United States

Phone: 12068840569

Email: nancy.lau@ seattlechildrens.org

\section{Abstract}

Background: Children, adolescents, and young adults with chronic conditions experience difficulties coping with disease-related stressors, comorbid mental health problems, and decreased quality of life. The COVID-19 pandemic has led to a global mental health crisis, and telemental health has necessarily displaced in-person care. However, it remains unknown whether such remote interventions are feasible or efficacious. We aimed to fill this research-practice gap.

Objective: In this systematic review, we present a synthesis of studies examining the feasibility and efficacy of telemental health interventions for youth aged $\leq 25$ years with chronic illnesses.

Methods: PubMed, Embase, Web of Science, PsycInfo, and Cochrane Database of Systematic Reviews were searched from 2008 to 2020. We included experimental, quasiexperimental, and observational studies of telemental health interventions designed for children, adolescents, and young adults aged $\leq 25$ years with chronic illnesses, in which feasibility or efficacy outcomes were measured. Only English-language publications in peer-reviewed journals were included. We excluded studies of interventions for caregivers or health care providers, mental health problems not in the context of a chronic illness, disease and medication management, and prevention programs for healthy individuals.

Results: We screened 2154 unique study records and 109 relevant full-text articles. Twelve studies met the inclusion criteria, and they represented seven unique telemental health interventions. Five of the studies included feasibility outcomes and seven included efficacy outcomes. All but two studies were pilot studies with relatively small sample sizes. Most interventions were based on cognitive behavioral therapy and problem-solving therapy. The subset of studies examining intervention feasibility concluded that telemental health interventions were appropriate, acceptable, and satisfactory to patients and their parents. Technology did not create barriers in access to care. For the subset of efficacy studies, evidence in support of the efficacy of telemental health was mixed. Significant heterogeneity in treatment type, medical diagnoses, and outcomes precluded a meta-analysis.

Conclusions: The state of the science for telemental health interventions designed for youth with chronic illnesses is in a nascent stage. Early evidence supports the feasibility of telehealth-based delivery of traditional in-person interventions. Few studies have assessed efficacy, and current findings are mixed. Future research should continue to evaluate whether telemental health may serve as a sustainable alternative to in-person care after the COVID pandemic. 
(JMIR Ment Health 2021;8(8):e30098) doi: 10.2196/30098

\section{KEYWORDS}

telehealth care; mental health; psychosocial issues; psychiatry; psychology; child; chronic disease

\section{Introduction}

Children, adolescents, and young adults with chronic medical conditions experience difficulties coping with disease-related stressors and decreased quality of life [1-3]. There is a strong association between physical and mental health in children, adolescents, and young adults, such that up to $60 \%$ of those with chronic illnesses are diagnosed with comorbid mental health disorders $[4,5]$. Common challenges include navigating diagnosis- and treatment-related distress, disruptions to normative development, changing family and peer relationships, and worries and uncertainty about the future [4-6]. The global COVID-19 pandemic has compounded these challenges and led to an increased risk of mental health symptoms, such as anxiety, depression, substance abuse, and posttraumatic stress, in healthy populations and worsening symptoms in those with pre-existing mental health disorders [7]. Further exacerbating negative impacts on psychological health, school closures have resulted in a lack of access to nonacademic support services (eg, sports and extracurricular programs and school mental health counselors), adjustment problems, and social isolation [8-10].

Overburdened health care systems have experienced a corresponding increase in demand for mental health services, and over 200 affected countries have inadequate resources to meet this influx $[11,12]$. Since the early stages of the pandemic, social distancing precautions have necessitated a shift in the mental health treatment standard of care from an in-person mode of delivery to telemental health (ie, via secure web-based videoconferencing platforms) [7]. Payor policy changes have been implemented to provide much needed care while ensuring the physical safety of patients and providers alike [13]. Projections suggest that US $\$ 250$ billion of health care spending in the United States could become telehealth-based after the COVID-19 pandemic [14].

The rapid adoption of telehealth in health care systems and insurance program coverage has helped ensure continuity in mental health care and availability of psychosocial services in response to escalating needs during the pandemic. A number of systematic reviews in adult populations have shown that videoconferencing psychotherapies are feasible and have comparable outcomes to in-person treatment, and for anxiety and depression in particular [15-17]. There is limited information regarding the feasibility and efficacy of telemental health services for children, adolescents, and young adults with chronic illnesses, but early findings are similarly promising to adult interventions. Existing pediatric telemental health research has been limited to case studies, single-site child psychiatry department implementation efforts, and reviews pertaining to the treatment of youth with mental health concerns not in the context of medical conditions [18-22].
In this systematic review, we aimed to answer the following research questions:

1. What is the evidence for the feasibility of telemental health in child, adolescent, and young adult chronic illness populations?

2. What is the evidence for the efficacy of telemental health in child, adolescent, and young adult chronic illness populations?

3. What types of in-person interventions and intervention components have been adapted to telemental health delivery?

\section{Methods}

\section{Data Sources}

An electronic database search was executed by a research librarian in five databases (PubMed/MEDLINE, Embase, Web of Science, PsycInfo, and Cochrane Database of Systematic Reviews) on May 29, 2020, for publications from 2008 to 2020. The list of keyword parameters was based on controlled vocabulary terms prespecified by each database. The search terms included those relevant to age demographics, telemedicine and telehealth, and chronic disease, utilizing the following Boolean [23] operators: (p?ediatric* OR child* OR youth* OR teen* OR preteen* OR preadolescent* OR adolescent* OR young adult*) AND (telehealth OR eHealth OR telemedicine OR online OR telecounsel* OR teletherapy*) AND (chronic* OR condition* OR disease* OR ill* OR sick* OR syndrom* OR chronic condition OR chronic disease OR chronic illness OR long term condition OR long term disease OR noncommunicable disease OR noncommunicable condition).

\section{Study Selection}

The inclusion criteria were as follows: (1) availability in English; (2) study published in a peer-reviewed journal; (3) experimental, quasiexperimental, or observational study in which feasibility and/or efficacy outcomes were reported; (4) telemental health interventions delivered via videoconferencing platforms; and (5) interventions designed for children, adolescents, or young adults aged $\leq 25$ years with a chronic disease (ie, a long-term medical condition lasting 3 months or longer [24]). We excluded studies of interventions that targeted caregivers or health care providers only, interventions that targeted mental health problems not in the context of a chronic illness, prevention programs for healthy individuals, and programs that targeted disease and medication management. In addition, we excluded nonpeer-reviewed publications (eg, dissertation manuscripts and conference abstracts) and study protocols for which no outcomes were reported.

First, we screened the titles and abstracts of studies retrieved for inclusion and exclusion. We then obtained the full texts of articles designated as potentially meeting the inclusion criteria to assess eligibility. Screening of all titles, abstracts, and full-text 
articles was first conducted by two independent coders (NL and $\mathrm{SW})$. Then, disagreements between the authors were discussed while referencing the original source material to reach consensus. For screening of titles and abstracts, interrater agreement between independent coders (NL and SW) was very good, reflected by a Cohen kappa of 0.84. For screening of full-text articles, interrater agreement between independent coders (NL and SW) was good, reflected by a Cohen kappa of 0.79. For articles meeting the inclusion criteria, we independently double coded relevant information from each study in pairs from a group of three (NL, SFC, and KF).

\section{Data Extraction and Synthesis}

Data were extracted using a shared Excel template. Relevant information from each study included study design, sample size, target illness, participant age range, type of control group (where applicable), intervention name, intervention type, facilitator credentials, parental involvement, 1:1 or group-based format, homework assignments, technological components, and results. Both significant and nonsignificant outcomes were reported; we included information on $P$ values and effect sizes if reported in the original study publication. After review of the articles meeting the inclusion criteria $(n=12)$, the team determined that heterogeneity in intervention type, study design, outcome variables, and measurement timepoints precluded a meta-analysis. Thus, we described the data in a narrative synthesis.

\section{Quality Assessment}

For the subset of included records that were efficacy studies, study quality was assessed by two independent coders from a group of three (NL, SFC, and KF) using the Cochrane Collaboration tool for assessing risk of bias [25]. The Cochrane tool evaluates the following seven evidence-based categories: random sequence generation (selection bias), allocation concealment (selection bias), blinding of participants and personnel (performance bias), blinding of outcome assessment (detection bias), incomplete outcome data (attrition bias), selective reporting (reporting bias), and other bias. We coded each category as low, high, or unclear risk of bias according to established standards in the Cochrane Handbook for Systematic Reviews of Interventions [26]. Support for judgment was directly quoted from the articles or published study protocols (where available) as relevant source materials. We utilized the well-established Grades of Recommendation, Assessment, Development, and Evaluation (GRADE) approach to evaluate the quality of evidence [27]. According to this approach, randomized trials start as high quality and are downgraded for limitations such as lack of allocation concealment; lack of blinding; attrition bias due to amount, nature, or handling of incomplete outcome data; and reporting bias. We coded a category as unclear if not enough information was available in the article to make a judgment. We resolved discrepancies in coding during regularly scheduled consensus meetings by referring back to the journal articles themselves.

\section{Results}

\section{Overview}

The search initially identified a total of 3330 articles (PubMed, 1410; Embase, 838; Web of Science, 390; PsycInfo, 607; and Cochrane Database of Systematic Reviews, 85). There were 1176 duplicates removed. This resulted in 2154 unique records screened, and 109 full-text articles were designated as potentially meeting the inclusion criteria. Review of the full-text articles resulted in 12 articles that met the criteria for inclusion. The results of the search and selection of studies are described in the PRISMA (Preferred Reporting Items for Systematic Reviews and Meta-Analyses) flow diagram (Figure 1).

Figure 1. PRISMA (Preferred Reporting Items for Systematic Reviews and Meta-Analyses) flow diagram.
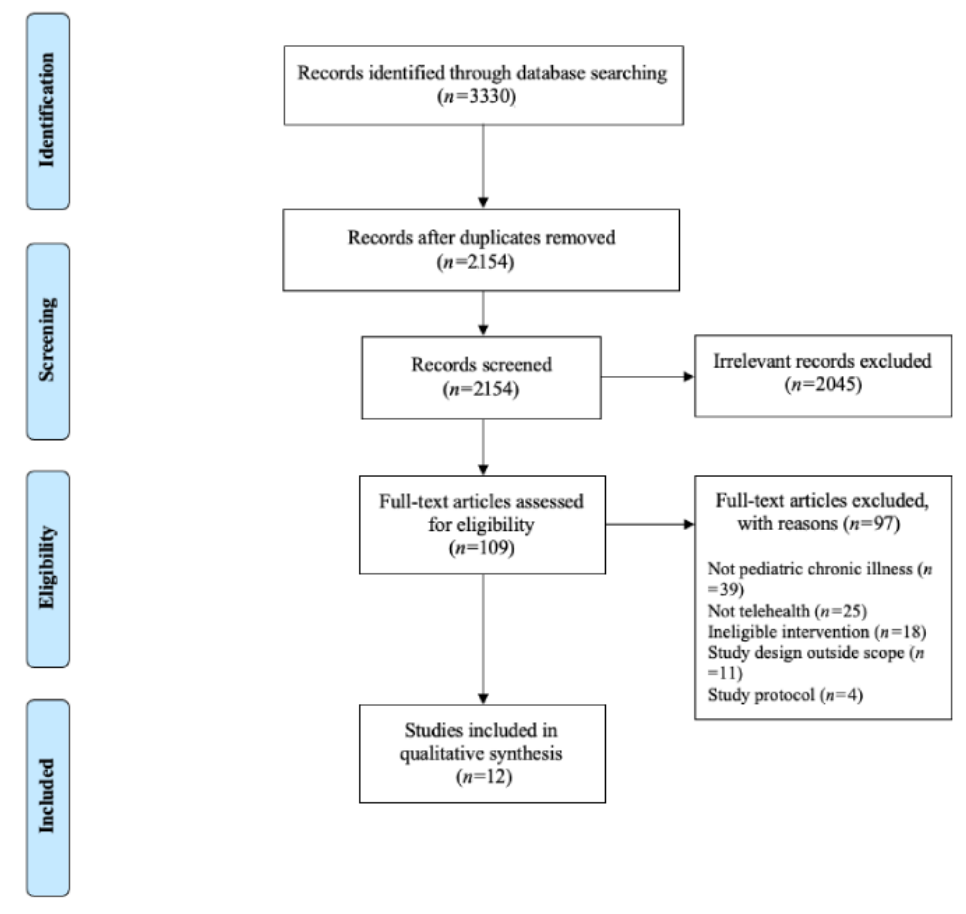


\section{Intervention Characteristics}

We found seven unique telemental health interventions that were developed and tested in Australia, Canada, and the United States (Tables 1 and 2). Five (71\%) were 1:1 interventions and the rest were group-based interventions. For group-based interventions, the number of facilitators ranged from 1 to 2 and the number of patients ranged from 3 to 9 per group. Four (57\%) of the interventions were delivered by psychologists; other facilitators included study personnel with training in the tested intervention $(n=2)$ and therapists at a master's level $(n=1)$.

Table 1. Videoconferencing interventions targeted for youth chronic illness populations.

\begin{tabular}{|c|c|c|c|c|c|c|c|c|}
\hline Source, year & Intervention name & Target illness & $\begin{array}{l}\text { Age } \\
\text { range, } \\
\text { years }\end{array}$ & $\begin{array}{l}\text { Country of } \\
\text { origin }\end{array}$ & $\begin{array}{l}\text { Underlying inter- } \\
\text { vention theory }\end{array}$ & $\begin{array}{l}\text { Facilitator creden- } \\
\text { tials }\end{array}$ & $\begin{array}{l}\text { Group } \\
\text { based }\end{array}$ & $\begin{array}{l}\text { Facilitator- } \\
\text { to-patient } \\
\text { ratio }\end{array}$ \\
\hline $\begin{array}{l}\text { Wade et al, } 2020 \\
\text { [28] } \\
\text { Moscato et al, } \\
2019 \text { [29] }\end{array}$ & A Survivor's Journey ${ }^{a}$ & $\begin{array}{l}\mathrm{AYA}^{\mathrm{b}} \text { pediatric } \\
\text { brain tumor sur- } \\
\text { vivors }\end{array}$ & $13-24^{\mathrm{c}}$ & $\begin{array}{l}\text { United } \\
\text { States }\end{array}$ & $\begin{array}{l}\text { Cognitive-behav- } \\
\text { ioral problem-solv- } \\
\text { ing therapy }\end{array}$ & $\begin{array}{l}\text { Licensed clinical } \\
\text { psychologist }\end{array}$ & No & $1: 1$ \\
\hline $\begin{array}{l}\text { Wade et al, } 2014 \\
\text { [30] } \\
\text { Wade et al, } 2015 \\
{[31]}\end{array}$ & $\begin{array}{l}\text { Counselor Assisted } \\
\text { Problem-Solving } \\
\text { (CAPS) intervention }\end{array}$ & $\begin{array}{l}\text { Adolescents } \\
\text { with traumatic } \\
\text { brain injury }\end{array}$ & $12-17$ & $\begin{array}{l}\text { United } \\
\text { States }\end{array}$ & $\begin{array}{l}\text { Family-based } \\
\text { problem-solving } \\
\text { therapy }\end{array}$ & $\begin{array}{l}\text { Licensed clinical } \\
\text { psychologist }\end{array}$ & Yes & $1: 1$ \\
\hline $\begin{array}{l}\text { Chadi et al, } 2018 \\
\text { [32] } \\
\text { Chadi et al, } 2019 \\
\text { [33] }\end{array}$ & $\begin{array}{l}\text { Mindful Awareness and } \\
\text { Resilience Skills for } \\
\text { Adolescents (MARS-A) } \\
\text { Program }^{\mathrm{d}}\end{array}$ & $\begin{array}{l}\text { Chronic medi- } \\
\text { cal or mental } \\
\text { health illness }\end{array}$ & $13-18$ & Canada & $\begin{array}{l}\text { Evidence-based } \\
\text { mindfulness }\end{array}$ & $\begin{array}{l}\text { Experienced per- } \\
\text { sonnel with } \\
\text { MARS-A specif- } \\
\text { ic training }\end{array}$ & Yes & $2: 9$ \\
\hline $\begin{array}{l}\text { Mcgill et al, } 2017 \\
\text { [34] } \\
\text { Sansom-Daly et al, } \\
2019 \text { [35] }\end{array}$ & Recapture Life & $\begin{array}{l}\text { AYA cancer } \\
\text { survivors }\end{array}$ & $15-25$ & Australia & $\begin{array}{l}\text { Cognitive behav- } \\
\text { ioral therapy }\end{array}$ & Psychologist & Yes & $1: 3-5$ \\
\hline $\begin{array}{l}\text { Wade et al, } 2018 \\
\text { [36] }\end{array}$ & $\begin{array}{l}\text { Social Participation and } \\
\text { Navigation (SPAN) } \\
\text { Program }\end{array}$ & $\begin{array}{l}\text { Adolescents } \\
\text { with acquired } \\
\text { brain injury }\end{array}$ & $14-22$ & $\begin{array}{l}\text { United } \\
\text { States }\end{array}$ & $\begin{array}{l}\text { Social skills, prob- } \\
\text { lem-solving thera- } \\
\text { py, goal setting }\end{array}$ & $\begin{array}{l}\text { Trained under- } \\
\text { graduate college } \\
\text { student coach }\end{array}$ & No & $1: 1$ \\
\hline $\begin{array}{l}\text { Wade et al, } 2011 \\
\text { [37] }\end{array}$ & $\begin{array}{l}\text { Teen Online Problem- } \\
\text { Solving (TOPS) Inter- } \\
\text { vention }\end{array}$ & $\begin{array}{l}\text { Adolescents } \\
\text { with traumatic } \\
\text { brain injury }\end{array}$ & $11-18$ & $\begin{array}{l}\text { United } \\
\text { States }\end{array}$ & $\begin{array}{l}\text { Family-based } \\
\text { problem-solving } \\
\text { therapy }\end{array}$ & $\begin{array}{l}\text { Licensed clinical } \\
\text { psychologist and } \\
\text { clinical psycholo- } \\
\text { gy PhD students }\end{array}$ & No & $1: 1$ \\
\hline $\begin{array}{l}\text { Ricketts et al, } 2016 \\
{[38]}\end{array}$ & $\begin{array}{l}\text { VoIP-delivered CBIT } \\
\text { (CBIT-VoIP) }\end{array}$ & $\begin{array}{l}\text { Youth with } \\
\text { chronic tic disor- } \\
\text { ders }\end{array}$ & $8-16$ & $\begin{array}{l}\text { United } \\
\text { States }\end{array}$ & $\begin{array}{l}\text { Comprehensive } \\
\text { behavioral interven- } \\
\text { tion for tics (CBIT) }\end{array}$ & $\begin{array}{l}\text { CBIT trained } \\
\text { therapist, master's } \\
\text { level }\end{array}$ & No & $1: 1$ \\
\hline
\end{tabular}

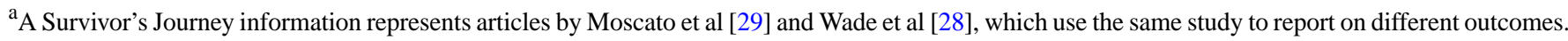
${ }^{\mathrm{b}} \mathrm{AYA}$ : adolescent and young adult.

${ }^{\mathrm{c}}$ This is the age range of the study sample used in analysis. The inclusion criteria specified an age range of 13-25.

${ }^{\mathrm{d}}$ MARS-A program information represents articles by Chadi et al [32,33], which are two studies of the same intervention. 
Table 2. Technology, intervention, and group components.

\begin{tabular}{|c|c|c|c|c|c|c|c|}
\hline \multirow[t]{2}{*}{ Source, year } & \multirow[t]{2}{*}{ Intervention name } & \multicolumn{3}{|c|}{ Technology components } & \multicolumn{3}{|c|}{ Intervention components } \\
\hline & & $\begin{array}{l}\text { Video platform } \\
\text { used }\end{array}$ & Provided device & Tech support & $\begin{array}{l}\text { Parents in- } \\
\text { volved }\end{array}$ & $\begin{array}{l}\text { Homework assign- } \\
\text { ments }\end{array}$ & Self-guided \\
\hline $\begin{array}{l}\text { Wade et al, } 2020 \\
{[28]}\end{array}$ & A Survivor's Journey ${ }^{\mathrm{a}}$ & Skype & Yes $^{b}$ & Yes $^{\mathrm{c}}$ & No & Yes & Yes \\
\hline \multicolumn{8}{|l|}{$\begin{array}{l}\text { Moscato et al, } \\
2019 \text { [29] }\end{array}$} \\
\hline $\begin{array}{l}\text { Wade et al, } 2014 \\
\text { [30] }\end{array}$ & CAPS intervention & Skype & Yes & $\mathrm{Yes}^{\mathrm{c}}$ & Yes & Yes & Yes \\
\hline \multicolumn{8}{|l|}{$\begin{array}{l}\text { Wade et al, } 2015 \\
\text { [31] }\end{array}$} \\
\hline $\begin{array}{l}\text { Chadi et al, } 2018 \\
\text { [32] }\end{array}$ & $\begin{array}{l}\text { Mindful Awareness and } \\
\text { Resilience Skills for }\end{array}$ & Zoom & No & Yes & No & Yes & No \\
\hline $\begin{array}{l}\text { Chadi et al, } 2019 \\
\text { [33] }\end{array}$ & $\begin{array}{l}\text { Adolescents (MARS-A) } \\
\text { Program }^{\mathrm{d}}\end{array}$ & & & & & & \\
\hline $\begin{array}{l}\text { McGill et al, } 2017 \\
\text { [34] }\end{array}$ & Recapture Life & WebEx & Yes $^{b}$ & No & Yes & Yes & No \\
\hline \multicolumn{8}{|l|}{$\begin{array}{l}\text { Sansom-Daly et al, } \\
2019 \text { [35] }\end{array}$} \\
\hline $\begin{array}{l}\text { Wade et al, } 2018 \\
\text { [36] }\end{array}$ & $\begin{array}{l}\text { Social Participation and } \\
\text { Navigation (SPAN) Pro- } \\
\text { gram }\end{array}$ & Skype & No & No & No & Yes & Yes \\
\hline $\begin{array}{l}\text { Wade et al, } 2011 \\
\text { [37] }\end{array}$ & $\begin{array}{l}\text { Teen Online Problem } \\
\text { Solving (TOPS) interven- } \\
\text { tion }\end{array}$ & Not specified & $\mathrm{Yes}^{\mathrm{b}, \mathrm{e}}$ & Yes $^{c}$ & Yes & Yes & Yes \\
\hline $\begin{array}{l}\text { Ricketts et al, } 2016 \\
{[38]}\end{array}$ & $\begin{array}{l}\text { VoIP-delivered CBIT } \\
\text { (CBIT-VoIP) }\end{array}$ & Skype & Yes $^{b}$ & Yes & Yes & Yes & No \\
\hline
\end{tabular}

${ }^{a} A$ Survivor's Journey information represents articles by Moscato et al [29] and Wade et al [28], which report on different outcomes from the same parent study.

${ }^{b}$ Provided to those who did not have one of their own.

${ }^{\mathrm{c}}$ Tutorial provided before the start of the intervention; no ongoing tech support.

${ }^{\mathrm{d}}$ MARS-A program information represents articles by Chadi et al [32,33], which are two studies of the same intervention.

${ }^{\mathrm{e}}$ High speed internet access provided to everyone.

All psychosocial interventions were adapted specifically for chronic medical conditions and designed to teach coping skills to facilitate adjustment to illness via treatment manuals. Interventions were primarily based on evidence-based cognitive behavioral therapy and problem-solving therapy. The specific coping skills targeted included cognitive restructuring, mindfulness, behavioral activation, social participation, goal setting, and problem solving to facilitate adjustment to illness. Manualized intervention content (ie, standardized treatment manuals documenting session-by-session objectives and procedures to ensure intervention fidelity across facilitators) provided a systematic approach for developing adaptive coping strategies and is the standard of practice for empirically supported psychotherapies. All interventions assigned homework to facilitate skills practice. Four $(57 \%)$ interventions contained self-guided online modules with disease-relevant resources in addition to regularly scheduled videoconference-based therapy sessions. For the subset of interventions with web content, participants met with a facilitator for weekly telemental health sessions. Online self-guided modules consisted of interactive didactic content, videos of patients discussing use of coping skills, and animated videos providing examples of how to directly apply coping skills to day-to-day life. Parents were active participants in family-based videoconferencing therapy sessions for $4(57 \%)$ of the interventions.

The video platforms used were Skype $(n=4)$, Cisco WebEx $(n=1)$, Zoom $(n=1)$, and unspecified $(n=1)$. Five $(71 \%)$ of the interventions provided devices to connect to video platforms for participants who needed them, and one intervention provided both devices and high-speed internet access for participants. Three $(43 \%)$ of the interventions provided an introductory tutorial on how to access and use the video platform program, and $2(29 \%)$ provided ongoing technological support.

\section{Participants}

Across all included studies, study sample sizes ranged from 14 to 132 . The age range of participants was from 8 to 25 years. The targeted chronic illnesses included brain tumor, cancer, traumatic brain injury, chronic tic disorder, and chronic illness (nondisease-specific intervention). The key study characteristics are summarized in Tables 3 and 4. 
Table 3. Original research publications reporting on feasibility outcomes.

\begin{tabular}{|c|c|c|c|c|c|c|}
\hline Source, year & $\begin{array}{l}\text { Intervention } \\
\text { name }\end{array}$ & Study type & $\begin{array}{l}\text { Sample } \\
\text { size }^{\mathrm{a}}\end{array}$ & $\begin{array}{l}\text { Age } \\
\text { range, } \\
\text { years }\end{array}$ & $\begin{array}{l}\text { How constructs were defined } \\
\text { and measured }\end{array}$ & Results \\
\hline $\begin{array}{l}\text { Moscato et } \\
\text { al, 2019 [29] }\end{array}$ & $\begin{array}{l}\text { A Survivor's } \\
\text { Journey }\end{array}$ & $\begin{array}{l}\text { Pilot feasibility } \\
\text { study }^{\mathrm{b}}\end{array}$ & 17 & $13-24$ & $\begin{array}{l}\text { Feasibility: Enrollment and } \\
\text { completion rates } \\
\text { Acceptability: Internally devel- } \\
\text { oped satisfaction survey of the } \\
\text { Teen Online Problem Solving } \\
\text { (TOPS) intervention on a 4- } \\
\text { point Likert scale. Overall } \\
\text { satisfaction ratings included } \\
\text { whether the program met ex- } \\
\text { pectations, what content was } \\
\text { most and least helpful, } \\
\text { whether the website was easy } \\
\text { to use, understand, and navi- }\end{array}$ & $\begin{array}{l}\text { Feasibility: } 50 \% \text { enrollment rate (which met } \\
\text { researchers' enrollment aim), and } 95 \% \text { complet- } \\
\text { ed core sessions, which exceeded the goal of } \\
\text { a } 75 \% \text { completion rate. } \\
\text { Acceptability: Exceeded the goal of } 75 \% \text { of } \\
\text { participants reporting satisfaction on most } \\
\text { items of the satisfaction survey (eg, every par- } \\
\text { ticipant reported that they would recommend } \\
\text { the program to others, website was easy to use } \\
\text { and navigate, and content was relevant to } \\
\text { them). Did not meet the goal of } 75 \% \text { of partic- } \\
\text { ipants rating the intervention above average in } \\
\text { usability on the System Usability Scale. }\end{array}$ \\
\hline
\end{tabular}

Chadi et al, Mindful Qualitative por- $18 \quad 13-18$ Acceptability/feasibility: Pro2018 [32] Awareness tion of random- gram exit interviews used to and Resilience ized mixed foster personal reflections Skills for Ado- methods trial about participants' experilescents (MARS-A) Program

McGill et al, Recapture 2017 [34] Life
Qualitative analysis of three-arm pilot randomized controlled trial (RCT) ences of the MARS-A program and qualitative analysis identified four themes from interview data.

$39^{\mathrm{d}} \quad 15-25 \quad$ Acceptability: Authors stated that therapeutic alliance (collaborative element of the patient-therapist dyad) and group cohesion (quality of interpersonal processes between group members and between group members and the therapist) are important to determine the acceptability of online models of psychosocial care.
Acceptability/feasibility: Themes describing experiences for both in-person and eHealth groups were as follows: creating a safe space; fostering peer support and connection; integrating mindfulness skills into daily life; and improving well-being through mindfulness. Based on qualitative results, they concluded that eHealth delivery of a mindfulness-based intervention may be an acceptable and feasible mode of delivery for adolescents with chronic illnesses.

Acceptability-group cohesion: All participants endorsed at least moderate group cohesion on all group cohesion items after the last session (that they shared important things, felt accepted and respected, and the program was the best way to get help, and it helped them gain a deeper understanding).

Acceptability-therapeutic alliance: All participants endorsed strong therapeutic alliance on all therapeutic alliance items, and it remained high over time from the first to last session (understanding, confidence, appreciation, and working correctly). Therapists endorsed strong therapeutic alliance on all therapeutic alliance items (participant comfort, rapport, openness, trust, peer to peer, motivation, and engagement); endorsed that participants had significantly increased openness, trust, and motivation from the first to last session $(P<.05)$; and endorsed that the items pertaining to participant comfort, rapport, peer-to-peer discussion, and engagement were strong and unchanged over time from the first to last session. 


\begin{tabular}{llllll}
\hline Source, year & $\begin{array}{l}\text { Intervention } \\
\text { name }\end{array}$ & Study type & $\begin{array}{l}\text { Sample } \\
\text { size }\end{array}$ & $\begin{array}{l}\text { Age } \\
\text { range, } \\
\text { years }\end{array}$ & $\begin{array}{l}\text { How constructs were defined } \\
\text { and measured }\end{array}$
\end{tabular}

\begin{tabular}{llll}
\hline Sansom- & Recapture & $\begin{array}{l}\text { Three-arm RCT } \\
\text { reporting on } \\
\text { Daly et al, }\end{array}$ & Life \\
$2019[35]^{\text {c }}$ & & $\begin{array}{l}\text { feasibility and } \\
\text { acceptability }\end{array}$ &
\end{tabular}

$\begin{array}{llll}\text { Wade et al, } & \text { Social Partici- } & \text { Nonrandomized } & 15 \\ 2018[36] & \text { pation and } & \text { pilot trial }^{\mathrm{e}} & \\ & \begin{array}{l}\text { Navigation } \\ \text { (SPAN) Pro- }\end{array} & \\ & & \\ & \text { gram } & \end{array}$

14-22 Feasibility: Number of sessions completed, and number of social participation goals achieved during the intervention.

Satisfaction: Internally developed measure to assess satisfaction with the program for participants and their parents
Feasibility: Recruitment rates Results: Recruitment rate of 30.41\% (45 ranacross sites; mean days to domized/148 approached), and $80 \%$ of particigroup commencement; medi- pants had access to all required technologies. an time for session commence- Individuals waited on average for 40 days ment; proportion of eligible, interested adolescents and young adults (AYAs) who had the technological equipment and internet access required to participate; number sessions and perceived impact on content delivery; time taken to check participants' between-session emotional safety using email/text inquiries; total number of additional catch up sessions contheir group sesion, recheduled group sessions, and scheduled group sessions outside of office hours.

Acceptability: Opt-in, enrollment, and retention rates, and participant engagement (total group sessions attended) and homework completion rates. Responded to two internally developed items "Was participation in this study beneficial to you in any way?" and "Was participation in this study burdensome for you in any way?" Qualitative analysis of open-ended questionnaire responses used to explore participants' experiences with the program.

(range 5-107) from completing the baseline questionnaire to commencing an online group with a sufficient number of peers. Sessions took a median of 4 minutes to commence, and $74 \%$ of sessions had all participants $\log$ on within 5 minutes of the scheduled start time. Six "catch up" sessions were delivered for participants unable to attend the scheduled group. Overall, 10 of 12 groups required sessions to be scheduled out-of-hours, representing 60 online sessions across the trial (approximately 90 hours). Technological difficulties were common, being experienced at least once in $71 \%$ of sessions, and $38 \%$ experienced two or more technological difficulties, but difficulties were rated as having a low impact on intervention delivery. The most common technological difficulties were poor quality audio and dropouts (43\% of sessions) and webcam freezing ( $43 \%$ of sessions). Of participants whose scores triggered a between-session telephone call for safety, all were telephoned within 48 hours. An average of 1.8 (range 1-4) email, text, and/or phone calls was required to confirm safety. Authors concluded that the findings support program feasibility.

Acceptability: Opt-in rate of 30\%. Enrollment rate of $87 \%$ of those who completed baseline, and completion rate of $92 \%$. High level of engagement with majority of participants attending at least 74\% (5/6) of sessions.

AYAs reported a high benefit and low burden of participation on open-ended questionnaire responses. Participants reported a completed average of $51 \%$ of program homework. Authors concluded that the findings support program acceptability.

Feasibility: Participants completed an average of $80 \%$ of sessions (range 3-10) and achieved an average of three social participation goals (range 1-7). Authors concluded that the findings support program feasibility.

Satisfaction: All participants "agreed" or

"strongly agreed" that the program was useful, were glad to do the program, and would recommend the program to others. All parents "agreed" or "strongly agreed" that they were glad to do the program and would recommend it to others. Authors concluded that the findings support program satisfaction.

\footnotetext{
${ }^{\mathrm{a}}$ Sample size used in the analyses.

${ }^{\mathrm{b}}$ Provides feasibility outcomes for the parent study; see also the study by Wade et al [28] in Table 4.

${ }^{\mathrm{c}}$ All technical problems were reported as quickly correctable without major impacts on overall sessions.

${ }^{\mathrm{d}}$ Although both Recapture Life studies are based on the same parent study, a subset of 39 participants was represented in the qualitative study (McGill et al [34]) and all participants were represented in the pilot randomized controlled trial (Sansom-Daly et al [35]).

${ }^{\mathrm{e}}$ Wade et al [36] is represented in Tables 3 and 4 due to reporting both feasibility and efficacy outcomes of interest.
} 
Table 4. Original research publications reporting on efficacy outcomes.

\begin{tabular}{|c|c|c|c|c|c|c|c|}
\hline Source, year & $\begin{array}{l}\text { Intervention } \\
\text { name }\end{array}$ & Study type & $\mathrm{RCT}^{\mathrm{a}}$ & $\begin{array}{l}\text { Control } \\
\text { group }\end{array}$ & $\begin{array}{l}\text { Sample } \\
\text { size }^{\text {b }}\end{array}$ & $\begin{array}{l}\text { Age } \\
\text { range, } \\
\text { years }\end{array}$ & Outcomes $^{c}$ \\
\hline $\begin{array}{l}\text { Wade et al, } \\
2020 \text { [28] }\end{array}$ & $\begin{array}{l}\text { A Survivor's } \\
\text { Journey }\end{array}$ & $\begin{array}{l}\text { Pilot feasibili- } \\
\text { ty study }\end{array}$ & No & N/A & 17 & $13-24$ & $\begin{array}{l}\text { Improved self-reported overall }(d=0.58, P=.01) \\
\text { and physical quality of life }(d=0.55, P<.01) \text { at } \\
\text { posttreatment. Improved parent-reported emotion- } \\
\text { al quality of life }(d=0.43, P=.03) \text { at posttreatment. }\end{array}$ \\
\hline $\begin{array}{l}\text { Wade et al, } \\
2014[30] \\
\text { Wade et al, }\end{array}$ & \multirow{2}{*}{$\begin{array}{l}\text { Counselor As- } \\
\text { sisted Problem- } \\
\text { Solving (CAPS) } \\
\text { intervention }\end{array}$} & \multirow{2}{*}{$\begin{array}{l}\text { Original RCT } \\
\text { RCT long- } \\
\text { term follow- } \\
\text { up }\end{array}$} & \multirow[t]{2}{*}{ Yes } & \multirow[t]{2}{*}{$\begin{array}{l}\text { Internet re- } \\
\text { source }\end{array}$} & \multirow[t]{2}{*}{132} & \multirow[t]{2}{*}{$12-17$} & $\begin{array}{l}\text { No differences between groups in self-reported } \\
\text { internalizing or externalizing symptoms at post- } \\
\text { treatment. }\end{array}$ \\
\hline 2015 [31] & & & & & & & $\begin{array}{l}\text { Posttreatment between groups: gains not sustained } \\
\text { for internalizing or externalizing symptoms at } 12- \\
\text { and } 18 \text {-month follow-ups. At the } 18 \text {-month fol- } \\
\text { low-up: In the CAPS group, internalizing prob- } \\
\text { lems improved for high school-age participants } \\
\text { only }(P=.03) \text {. }\end{array}$ \\
\hline
\end{tabular}

\begin{tabular}{|c|c|c|c|c|c|c|c|}
\hline $\begin{array}{l}\text { Chadi et al, } \\
2019 \text { [33] }\end{array}$ & $\begin{array}{l}\text { Mindful Aware- } \\
\text { ness and Re- } \\
\text { silience Skills } \\
\text { for Adolescents } \\
\text { (MARS-A) Pro- } \\
\text { gram }\end{array}$ & Pilot RCT & Yes & $\begin{array}{l}\text { In-person } \\
\text { MARS-A }\end{array}$ & 14 & $13-18$ & $\begin{array}{l}\text { No differences between groups at posttreatment } \\
\text { in self-reported anxiety and depression. Reduced } \\
\text { pre-post anxiety and depression for the eHealth } \\
\text { group (Cohen } d=0.934, P=.048 \text { ); improvements } \\
\text { not sustained at a } 2 \text {-month follow-up. Similar } \\
\text { frequency and duration of the mindfulness practice } \\
\text { between groups at posttreatment. }\end{array}$ \\
\hline $\begin{array}{l}\text { Wade et al, } \\
2018 \text { [36] }\end{array}$ & $\begin{array}{l}\text { Social Participa- } \\
\text { tion and Naviga- } \\
\text { tion (SPAN) } \\
\text { Program }\end{array}$ & Pilot trial & No & $N / A^{d}$ & 15 & $14-22$ & $\begin{array}{l}\text { Increase in parent-reported frequency of social } \\
\text { participation }(d=1.11, P=.01) \text {, but not for teens at } \\
\text { posttreatment. Increase in teen-reported confi- } \\
\text { dence in social participation }(d=1.45, P<.01) \text { but } \\
\text { not for parents at posttreatment. Decline in parent- } \\
\text { reported total problems }(d=0.96, P<.01) \text {, internal- } \\
\text { izing problems }(d=0.73, P=.05) \text {, externalizing } \\
\text { problems }(d=0.79, P=.02) \text {, and social problems } \\
(d=0.82, P=.02) \text {, but no differences for adolescent- } \\
\text { reported problems at posttreatment. No significant } \\
\text { differences in the levels of social competence and } \\
\text { confidence in the ability to manage emotions re- } \\
\text { ported by teens or parents at posttreatment. }\end{array}$ \\
\hline $\begin{array}{l}\text { Wade et al, } \\
2011 \text { [37] }\end{array}$ & $\begin{array}{l}\text { Teen Online } \\
\text { Problem-Solv- } \\
\text { ing (TOPS) In- } \\
\text { tervention }\end{array}$ & RCT & Yes & $\begin{array}{l}\text { Internet re- } \\
\text { source }\end{array}$ & 35 & $11-18$ & $\begin{array}{l}\text { No differences between groups in adolescent-re- } \\
\text { ported parent-teen conflict, and adolescent- and } \\
\text { parent-reported internalizing and externalizing } \\
\text { symptoms at posttreatment. TOPS reduced parent- } \\
\text { reported conflict compared to controls }(P=.002) \\
\text { at posttreatment. }\end{array}$ \\
\hline \multirow[t]{3}{*}{$\begin{array}{l}\text { Ricketts et } \\
\text { al, } 2016 \text { [38] }\end{array}$} & \multirow[t]{3}{*}{$\begin{array}{l}\text { VoIP-delivered } \\
\text { CBIT (CBIT- } \\
\text { VoIP) }\end{array}$} & \multirow[t]{3}{*}{ Pilot RCT } & \multirow[t]{3}{*}{ Yes } & \multirow[t]{3}{*}{$\begin{array}{l}\text { Waitlist con- } \\
\text { trol }\end{array}$} & \multirow[t]{3}{*}{20} & \multirow[t]{3}{*}{$8-16$} & $\begin{array}{l}\text { Improved the Yale Global Tic Severity Scale score } \\
\text { relative to controls }(d=0.90, P<.01 \text {; partial } \\
\left.\eta^{2}=0.15, P<.05\right) \text { at posttreatment. Higher response } \\
\text { in the Clinical Global Impression-Improvement }\end{array}$ \\
\hline & & & & & & & $\begin{array}{l}\text { Scale in the treatment group }\left(\chi^{2}=0.33, P<.05 \text {, }\right. \\
\Phi=0.41) \text { at posttreatment. }\end{array}$ \\
\hline & & & & & & & $\begin{array}{l}\text { Improved Parent Tic Questionnaire score }(d=1.38 \text {, } \\
\left.P<.001 \text {; and partial } \eta^{2}=0.26, P<.05\right) \text { at posttreat- } \\
\text { ment. }\end{array}$ \\
\hline
\end{tabular}

${ }^{\mathrm{a}} \mathrm{RCT}$ : randomized controlled trial.

${ }^{\mathrm{b}}$ Sample size used in study analyses.

${ }^{\mathrm{c}}$ Statistically significant outcomes are reported with $P<.05 . d$ represents Cohen $d . \eta^{2}$ is eta-squared. The two statistics are measures of effect size. Effect sizes are reported if information was included in the original study publication.

${ }^{\mathrm{d}} \mathrm{N} / \mathrm{A}$ : not applicable.

\section{Feasibility Outcomes}

Based on the seminal work of Bowen et al, there is no consensus regarding how feasibility is defined and measured [39]. Due to few published standards, guides, and thresholds upon which to test and establish feasibility of an intervention, study teams when designing feasibility studies create their own internal thresholds regarding what they determine to be important and 
appropriate for their specific intervention and target population. Across the five studies examining intervention feasibility included in our review, some authors used and operationalized acceptability and feasibility interchangeably, others used and operationalized acceptability and satisfaction interchangeably, and still others used and operationalized all three as distinct constructs. In Table 3, we provide detailed information on how constructs of feasibility, acceptability, and satisfaction were defined and measured by the original authors of the included studies, and their respective results. Although, as expected, we did not observe consensus across all studies in their internal thresholds, common benchmarks included enrollment, adherence, and completion rates established a priori in order to determine feasibility (ie, addressing the question of "can this be done?") and use of internally developed measures or qualitative exit interviews to measure program acceptability and satisfaction (eg, whether participants enjoyed the program, whether participants benefited from the program, whether the program met their goals, and whether they would recommend the program to others). All studies reported high feasibility, acceptability, and satisfaction of telemental health interventions based on their own a priori internally established thresholds [29,32,34-36].

Sample sizes across studies ranged from 15 to 45 . Authors reported that enrollment and program completion rates met prespecified target goals, with $>30 \%$ enrollment and $>70 \%$ program completion rates across studies. Patients endorsed the high benefit and low burden of participation and satisfaction with the program, and mentioned they would recommend the program to others on Likert-scale measures (ie, "agreed" or "strongly agreed" with all item measures) and/or program exit interviews. In group-based telemental health interventions, patients endorsed experiencing a sense of support, trust, rapport, and connection with the facilitator and other group members on therapeutic alliance measures and/or qualitative interviews. For the Social Participation and Navigation (SPAN) program, although patients and parents reported high levels of satisfaction and enjoyment with participation, parents were more likely than their children to report that the program was useful [36]. Across all studies, technological difficulties were reported to have a low impact on intervention delivery and treatment satisfaction. However, of note, all studies examining feasibility were conducted with participants aged 13 years or older.

\section{Efficacy Outcomes}

There were seven efficacy studies with sample sizes ranging from 14 to 132; five had randomized designs [30,31,33,37,38] and two were prospective cohort studies $[28,36]$ (Table 4). Of the randomized trials, three were compared to internet resource comparison groups [30,31,37], one to an in-person version of the videoconference-based intervention [33], and one to a waitlist control group [38]. Five $(71 \%)$ of the efficacy studies were pilot studies with small sample sizes (ie, $\leq 35$ participants) $[28,29,33,36,38]$. Four of the studies collected both patient- and parent-reported outcome measures [28,36-38]. In our review, there was a significant amount of heterogeneity among outcomes targeted by specific interventions and corresponding treatment effects. All efficacy studies had a primary focus on psychosocial/mental health outcomes. One of the prospective cohort studies also measured physical outcomes (ie, overall and physical quality of life) [28]. Outcome measures across the five randomized trial studies were variable (ie, anxiety, depression, internalizing problems, externalizing problems, behavioral symptoms, and parent-teen conflict) [30,31,33,37,38]. Treatment outcome assessment timeframes were generally assessed immediately after treatment [28,30,33,36-38]. One trial reported on outcomes at a 2-month follow-up [33], and another trial reported on outcomes at a 12-month/18-month follow-up [31].

For the two prospective cohort studies, youth and parents reported some improvements in patient mental health well-being and functioning at posttreatment $[28,36]$. For the first study of a cognitive behavioral problem-solving intervention (sample size $=17$ ), patients reported significant improvements in emotional, physical, and overall quality of life (medium to large effects), whereas parents reported significant improvements in patient emotional quality of life only (medium effect) [28]. For the second study of a social skills and problem-solving intervention (sample size $=15$ ), patients reported significant improvements in confidence in social participation only (large effect), whereas parents reported significant improvements in patient frequency of social participation, internalizing problems, externalizing problems, social problems, and total problems (large effects) [36].

Of the randomized trial studies, four compared the intervention of interest with an active comparison group [30,31,33,37] and one with a waitlist control [38]. In the waitlist control trial (sample size=20), a cognitive behavioral intervention was associated with significant improvements in patient- and parent-reported behavioral symptoms (large effect) [38]. In a second trial testing a problem-solving intervention compared to an active internet resource comparison group (sample size=35), there were no significant group differences in patient-reported parent-teen conflict or patient- and parent-reported internalizing and externalizing symptoms; the problem-solving intervention demonstrated significant improvements in parent-reported parent-teen conflict only [37]. In the only trial to utilize a comparison group of face-to-face delivery of the same mindfulness intervention (sample size $=14$ ), both modes of delivery resulted in improvements in patient-reported posttreatment anxiety and depression with no significant differences between groups; improvements were not sustained at a 2-month follow-up [33]. Two studies of a problem-solving intervention compared to an internet resource comparison group (sample size=132) found no differences between groups in patient-reported internalizing and externalizing symptoms at posttreatment [30] and longer-term follow-up (12-month and 18-month follow-ups) [31].

\section{Risk of Bias}

Risk of bias was evaluated for all efficacy studies (Figure 2). Of the seven studies, five reported random sequence generation and allocation concealment (ie, the randomized trials). For the blinding of participants and personnel, and blinding of outcome assessment domains, four were low risk and three were high risk; the high-risk studies consisted of study designs with no control group or a waitlist control group. For attrition bias, five were low risk and two were high risk. For selective reporting 
bias, two were low risk, one was high risk, and four were unclear; studies were rated as unclear due to a lack of clinical trial registration or a published protocol. For other bias, four were considered low risk and three were high risk.

Figure 2. Risk of bias.

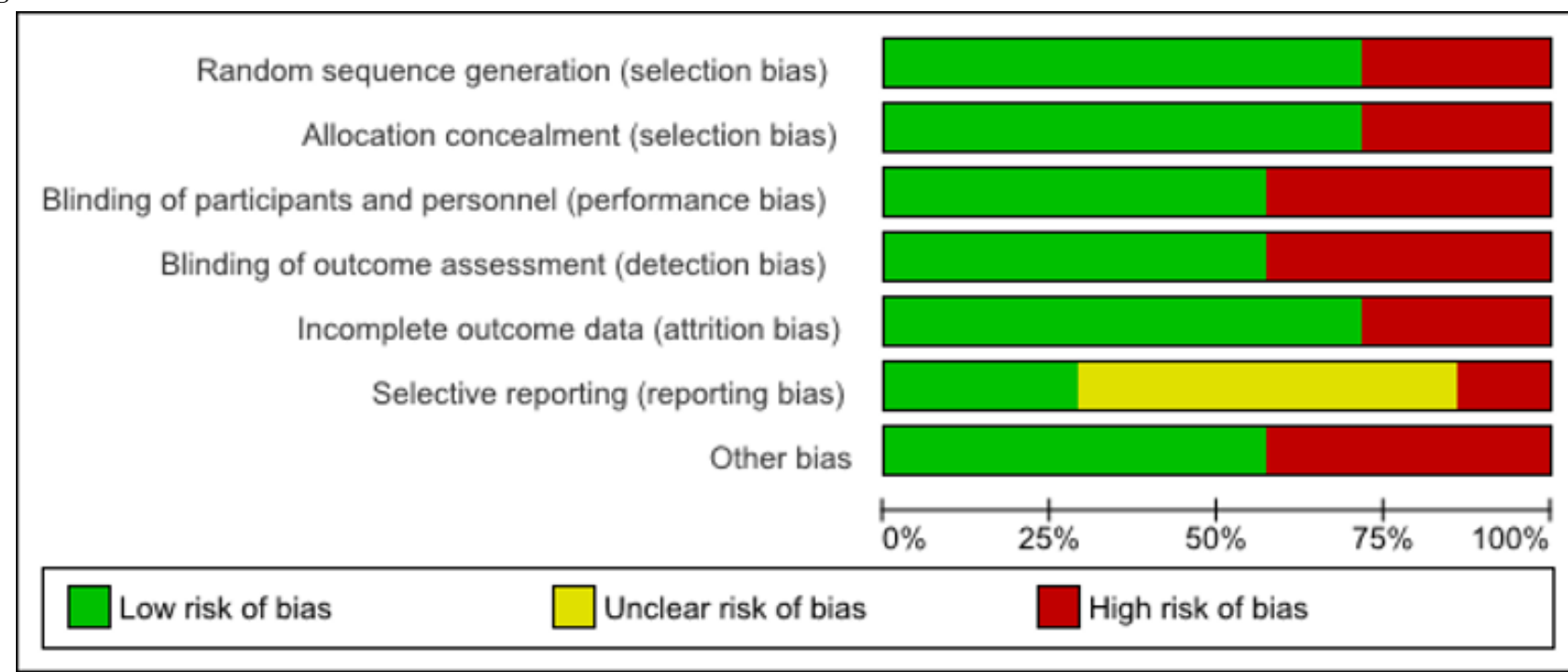

\section{Discussion}

\section{Principal Findings}

Chronic illnesses are commonly associated with comorbid mental health problems/disorders, including anxiety, stress, depression, maladjustment, and poor coping skills [2,4]. Further exacerbating baseline disease-related stressors, the COVID-19 pandemic has perpetuated a global mental health crisis and a corresponding increase in the demand for services [11]. Telemental health has become the standard of care since March of 2020, and may provide a cost-effective, scalable, and sustainable means of remote health care delivery [40]. This is the first systematic review to summarize the research evidence in support of the feasibility and efficacy of telemental health interventions for children, adolescents, and young adults with chronic illnesses.

In this article, we identified 12 studies on telemental health interventions. The interventions focused on evidence-based treatment strategies, including mindfulness, cognitive behavioral, and problem-solving strategies, across a broad range of target illnesses and psychosocial outcomes. Five (42\%) of the studies included feasibility outcomes and 7 (58\%) included efficacy outcomes. All but two studies were pilot studies with relatively small sample sizes. Across the small number of identified studies, telemental health interventions seemed to be appealing and acceptable for patients and parents alike. Although navigating videoconferencing platforms did not present technological barriers to treatment attendance or engagement, it is important to note that such findings were reported for studies with teenagers and young adults only who are understandably more tech savvy than younger cohorts. Single-cohort or waitlist control pilot studies examining the efficacy of telemental health interventions showed early promise and medium to large treatment effects. In randomized trials with active comparison conditions, there was little evidence of significant treatment effects across a range of mental health symptoms, and few studies included long-term outcome assessments. Only one trial compared face-to-face and telemental health delivery of the same intervention; both modes of delivery were similarly efficacious and improvements were not sustained at longer-term follow-up.

Together, this set of preliminary studies examining feasibility and efficacy provides early evidence that (1) telemental health interventions may be appropriate and acceptable to patients and their parents; (2) videoconferencing platforms may not present technological barriers to engagement and use; and (3) there is some modest early evidence in support of the efficacy of telemental health interventions, but preliminary findings are mixed. Our findings are consistent with previous reviews suggesting that telehealth may be appropriate and efficacious for adults with chronic conditions and for the delivery of mental health care $[41,42]$.

\section{Limitations}

Some limitations need to be considered. First, relatively few papers have been published on telemental health feasibility and efficacy among children, adolescents, and young adults with chronic illnesses. This suggests that the science lags behind its rapid rate of adoption in clinical settings. Second, most papers were pilot studies with small sample sizes and were underpowered to detect clinically or statistically significant treatment effects. Third, given the heterogeneity of treatment type, disease target, measurement timepoints, and mental health outcome measures, we were unable to perform a meta-analysis to quantify treatment effects. Fourth, approximately one-third of studies did not report on the racial or ethnic distribution of their sample, and those that did reported that the majority of participants were white. Similarly, none of the studies reported on the rurality of their sample. Fifth, we limited our study to English-language publications. Thus, the generalizability of the findings remains unclear. Sixth, it was not possible to examine age and developmental differences in treatment effects due to the small number of included studies and specific interventions 
developed and tested with a wide age range of patients. This limitation is consistent with a previous review that found little research assessing age and developmental patterns in coping with chronic illnesses [6]. Finally, our study was limited to peer-reviewed published articles and did not consider unpublished gray literature, such as conference abstracts and dissertations, which may have led to the identification of additional studies.

\section{Future Directions}

Future research should extend beyond feasibility and early efficacy pilot studies to assess how telemental health delivery compares to in-person care in therapeutic alliance and rapport building, treatment engagement and treatment drop-out rates, and efficacy/effectiveness in large-scale randomized trials. Although some preliminary evidence suggests positive effects associated with telehealth delivery, it is important to examine the relative benefits and costs associated with remote interventions. Telehealth may not be an appropriate delivery format for all patients. Some patients may respond better to or prefer in-person care, experience higher homework compliance, have lower dropout rates, and/or establish a stronger therapeutic alliance with a provider in a face-to-face meeting. Important future research directions include the development of the best screening processes to match patient characteristics to care delivery preferences in order to optimize outcomes. Patient characteristics with the potential to impact care delivery that warrant further exploration include age and developmental stage, acuity of mental health needs, chronic illness diagnosis and illness narrative, and medical treatment.
Evidence-based strategies proven to be effective when deployed through traditional in-person care may require iterative intervention adaptations to successfully translate treatment effects to telehealth modes of delivery. It may not be as straightforward as simply delivering the same manualized protocols via Skype, Zoom, or WebEx, and the optimal balance between traditional face-to-face care and remote delivery should be further examined. Equity in access to telemental health should also be examined, as some research teams supplied videoconferencing capable devices and high-speed internet access to participants who needed them, and such an approach may not be scalable as the standard of care. Ultimately, this study and future studies will help inform whether, for whom, and under what treatment conditions telemental health has the potential to serve as a sustainable long-term alternative to in-person care after the COVID-19 pandemic.

\section{Conclusions}

The strengths of this paper include the systematic approach to synthesizing the breadth of literature across chronic illness populations and the timely focus on telehealth, which has displaced in-person treatment as the standard of care in the context of the COVID-19 pandemic. Our findings suggest that although COVID-19 has necessitated remote treatment delivery, and patients and families may find this mode of delivery to be engaging and satisfactory, the state of the science is in a nascent stage and there is much to be learned about whether such interventions work, for whom they work, and in what contexts they work, as well as how they compare to in-person treatments.

\section{Acknowledgments}

NL is funded as an Implementation Science Scholar through the National Heart, Lung, and Blood Institute of the National Institutes of Health (grant number: 5K12 HL137940-02). The opinions herein represent those of the authors and not necessarily those of the funders.

\section{Conflicts of Interest}

None declared.

\section{References}

1. Warschburger P, Hänig J, Friedt M, Posovszky C, Schier M, Calvano C. Health-related quality of life in children with abdominal pain due to functional or organic gastrointestinal disorders. J Pediatr Psychol 2014;39(1):45-54. [doi: 10.1093/jpepsy/jst070] [Medline: 24055816]

2. Wallander JL, Varni JW. Effects of pediatric chronic physical disorders on child and family adjustment. J Child Psychol Psychiatry 1998 Jan;39(1):29-46. [Medline: 9534085]

3. Yeo M, Sawyer S. Chronic illness and disability. BMJ 2005 Mar 26;330(7493):721-723 [FREE Full text] [doi: 10.1136/bmj.330.7493.721] [Medline: 15790645]

4. Butler A, Van Lieshout RJ, Lipman EL, MacMillan HL, Gonzalez A, Gorter JW, et al. Mental disorder in children with physical conditions: a pilot study. BMJ Open 2018 Jan 03;8(1):e019011 [FREE Full text] [doi: 10.1136/bmjopen-2017-019011] [Medline: 29301763]

5. Barker MM, Beresford B, Bland M, Fraser LK. Prevalence and Incidence of Anxiety and Depression Among Children, Adolescents, and Young Adults With Life-Limiting Conditions: A Systematic Review and Meta-analysis. JAMA Pediatr 2019 Sep 01;173(9):835-844 [FREE Full text] [doi: 10.1001/jamapediatrics.2019.1712] [Medline: $\underline{31282938]}$

6. Compas BE, Jaser SS, Dunn MJ, Rodriguez EM. Coping with chronic illness in childhood and adolescence. Annu Rev Clin Psychol 2012 Apr 27;8(1):455-480 [FREE Full text] [doi: 10.1146/annurev-clinpsy-032511-143108] [Medline: 22224836]

7. Moreno C, Wykes T, Galderisi S, Nordentoft M, Crossley N, Jones N, et al. How mental health care should change as a consequence of the COVID-19 pandemic. Lancet Psychiatry 2020 Sep;7(9):813-824 [FREE Full text] [doi: 10.1016/S2215-0366(20)30307-2] [Medline: 32682460] 
8. Lee J. Mental health effects of school closures during COVID-19. Lancet Child Adolesc Health 2020 Jun;4(6):421 [FREE Full text] [doi: 10.1016/S2352-4642(20)30109-7] [Medline: 32302537]

9. Razai MS, Oakeshott P, Kankam H, Galea S, Stokes-Lampard H. Mitigating the psychological effects of social isolation during the covid-19 pandemic. BMJ 2020 May 21;369:m1904. [doi: 10.1136/bmj.m1904] [Medline: 32439691]

10. Hoffman JA, Miller EA. Addressing the Consequences of School Closure Due to COVID-19 on Children's Physical and Mental Well-Being. World Med Health Policy 2020 Aug 20;12(3):300-310 [FREE Full text] [doi: 10.1002/wmh3.365] [Medline: 32904951]

11. Anjum S, Ullah R, Rana MS, Khan HA, Memon FS, Ahmed Y, et al. COVID-19 Pandemic: A Serious Threat for Public Mental Health Globally. Psychiatr Danub 2020 Aug 12;32(2):245-250 [FREE Full text] [doi: 10.24869/psyd.2020.245] [Medline: 32796793]

12. Ćosić K, Popović S, Šarlija M, Kesedžić I. Impact of Human Disasters and COVID-19 Pandemic on Mental Health: Potential of Digital Psychiatry. Psychiatr Danub 2020 Apr 15;32(1):25-31 [FREE Full text] [doi: 10.24869/psyd.2020.25] [Medline: 32303026]

13. Ramtekkar U, Bridge JA, Thomas G, Butter E, Reese J, Logan E, et al. Pediatric Telebehavioral Health: A Transformational Shift in Care Delivery in the Era of COVID-19. JMIR Ment Health 2020 Sep 18;7(9):e20157 [FREE Full text] [doi: 10.2196/20157] [Medline: 32525485]

14. Bestsennyy O, Gilbert G, Harris A, Rost J. Telehealth: a quarter-trillion-dollar post-COVID-19 reality? McKinsey \& Company. 2021. URL: https://www.mckinsey.com/industries/healthcare-systems-and-services/our-insights/ telehealth-a-quarter-trillion-dollar-post-covid-19-reality [accessed 2021-02-01]

15. Backhaus A, Agha Z, Maglione ML, Repp A, Ross B, Zuest D, et al. Videoconferencing psychotherapy: a systematic review. Psychol Serv 2012 May;9(2):111-131. [doi: 10.1037/a0027924] [Medline: 22662727]

16. Rees CS, Maclaine E. A Systematic Review of Videoconference - Delivered Psychological Treatment for Anxiety Disorders. Australian Psychologist 2020 Nov 12;50(4):259-264. [doi: 10.1111/ap.12122]

17. García-Lizana F, Muñoz-Mayorga I. Telemedicine for depression: a systematic review. Perspect Psychiatr Care 2010 Apr;46(2):119-126. [doi: 10.1111/j.1744-6163.2010.00247.x] [Medline: 20377799]

18. Sharma A, Sasser T, Schoenfelder Gonzalez E, Vander Stoep A, Myers K. Implementation of Home-Based Telemental Health in a Large Child Psychiatry Department During the COVID-19 Crisis. J Child Adolesc Psychopharmacol 2020 Sep 01;30(7):404-413. [doi: 10.1089/cap.2020.0062] [Medline: 32639849]

19. Duncan AB, Velasquez SE, Nelson E. Using videoconferencing to provide psychological services to rural children and adolescents: a review and case example. J Clin Child Adolesc Psychol 2014 Sep 30;43(1):115-127. [doi: 10.1080/15374416.2013.836452] [Medline: 24079653]

20. Gloff NE, LeNoue SR, Novins DK, Myers K. Telemental health for children and adolescents. Int Rev Psychiatry 2015 Nov 05;27(6):513-524. [doi: 10.3109/09540261.2015.1086322] [Medline: 26540584]

21. Nelson E, Patton S. Using Videoconferencing to Deliver Individual Therapy and Pediatric Psychology Interventions with Children and Adolescents. J Child Adolesc Psychopharmacol 2016 Apr;26(3):212-220 [FREE Full text] [doi: 10.1089/cap.2015.0021] [Medline: 26745607]

22. Pesämaa L, Ebeling H, Kuusimäki ML, Winblad I, Isohanni M, Moilanen I. Videoconferencing in child and adolescent telepsychiatry: a systematic review of the literature. J Telemed Telecare 2004 Jun 24;10(4):187-192. [doi: 10.1258/1357633041424458] [Medline: 15273027 ]

23. Rousseau GK, Jamieson BA, Rogers WA, Mead SE, Sit RA. Assessing the usability of on-line library systems. Behaviour \& Information Technology 1998 Jan;17(5):274-281. [doi: 10.1080/014492998119346]

24. Bernell S, Howard SW. Use Your Words Carefully: What Is a Chronic Disease? Front Public Health 2016 Aug 02;4:159 [FREE Full text] [doi: 10.3389/fpubh.2016.00159] [Medline: 27532034]

25. Higgins JPT, Altman DG, Gøtzsche PC, Jüni P, Moher D, Oxman AD, Cochrane Bias Methods Group, Cochrane Statistical Methods Group. The Cochrane Collaboration's tool for assessing risk of bias in randomised trials. BMJ 2011 Oct 18;343(oct18 2):d5928-d5928 [FREE Full text] [doi: 10.1136/bmj.d5928] [Medline: 22008217]

26. Higgins J, Thomas J, Chandler J, Cumpston M, Li T, Page M, et al. Cochrane Handbook for Systematic Reviews of Interventions. New York, NY: John Wiley \& Sons; 2019.

27. Guyatt GH, Oxman AD, Vist G, Kunz R, Brozek J, Alonso-Coello P, et al. GRADE guidelines: 4. Rating the quality of evidence--study limitations (risk of bias). J Clin Epidemiol 2011 Apr;64(4):407-415. [doi: 10.1016/j.jclinepi.2010.07.017] [Medline: 21247734]

28. Wade SL, Narad ME, Moscato EL, LeBlond EI, King JA, Raj SP, et al. A Survivor's Journey: Preliminary efficacy of an online problem-solving therapy for survivors of pediatric brain tumor. Pediatr Blood Cancer 2020 Feb 13;67(2):e28043. [doi: $10.1002 /$ pbc. 28043] [Medline: $\underline{31724307]}$

29. Moscato EL, Miley AE, LeBlond EI, King JA, Raj SP, Narad ME, et al. Feasibility and acceptability of an online problem-solving therapy intervention for adolescent and young adult brain tumor survivors. Clinical Practice in Pediatric Psychology 2019 Mar;7(1):68-78. [doi: 10.1037/cpp0000265] 
30. Wade S, Stancin T, Kirkwood M, Brown T, McMullen K, Taylor H. Counselor-assisted problem solving (CAPS) improves behavioral outcomes in older adolescents with complicated mild to severe TBI. J Head Trauma Rehabil 2014;29(3):198-207 [FREE Full text] [doi: 10.1097/HTR.0b013e31828f9fe8] [Medline: 23640543]

31. Wade SL, Taylor HG, Cassedy A, Zhang N, Kirkwood MW, Brown TM, et al. Long-Term Behavioral Outcomes after a Randomized, Clinical Trial of Counselor-Assisted Problem Solving for Adolescents with Complicated Mild-to-Severe Traumatic Brain Injury. J Neurotrauma 2015 Jul 01;32(13):967-975 [FREE Full text] [doi: 10.1089/neu.2014.3684] [Medline: 25738891]

32. Chadi N, Weisbaum E, Malboeuf-Hurtubise C, Ahola Kohut S, Viner C, Kaufman M, et al. Can the Mindful Awareness and Resilience Skills for Adolescents (MARS-A) Program Be Provided Online? Voices from the Youth. Children (Basel) 2018 Aug 28;5(9) [FREE Full text] [doi: 10.3390/children5090115] [Medline: 30154368]

33. Chadi N, Weisbaum E, Malboeuf-Hurtubise C, Kohut SA, Viner C, Palaniyar N, et al. In-person vs. eHealth Mindfulness-based Intervention for Adolescents with Chronic Illnesses: A Pilot Randomized Trial. APS 2019 May 31;9(1):11-23. [doi: 10.2174/2210676608666181031102235]

34. McGill BC, Sansom-Daly UM, Wakefield CE, Ellis SJ, Robertson EG, Cohn RJ. Therapeutic Alliance and Group Cohesion in an Online Support Program for Adolescent and Young Adult Cancer Survivors: Lessons from "Recapture Life". J Adolesc Young Adult Oncol 2017 Dec;6(4):568-572. [doi: 10.1089/jayao.2017.0001] [Medline: 28581346]

35. Sansom-Daly UM, Wakefield CE, Bryant RA, Patterson P, Anazodo A, Butow P, Recapture Life Working Party. Feasibility, acceptability, and safety of the Recapture Life videoconferencing intervention for adolescent and young adult cancer survivors. Psychooncology 2019 Feb 28;28(2):284-292. [doi: 10.1002/pon.4938] [Medline: 30414219]

36. Wade SL, Bedell G, King JA, Jacquin M, Turkstra LS, Haarbauer-Krupa J, et al. Social Participation and Navigation (SPAN) program for adolescents with acquired brain injury: Pilot findings. Rehabil Psychol 2018 Aug;63(3):327-337 [FREE Full text] [doi: 10.1037/rep0000187] [Medline: 30024207$]$

37. Wade SL, Walz NC, Carey J, McMullen KM, Cass J, Mark E, et al. Effect on behavior problems of teen online problem-solving for adolescent traumatic brain injury. Pediatrics 2011 Oct 02;128(4):e947-e953 [FREE Full text] [doi: 10.1542/peds.2010-3721] [Medline: 21890828]

38. Ricketts EJ, Goetz AR, Capriotti MR, Bauer CC, Brei NG, Himle MB, Snorrason, et al. A randomized waitlist-controlled pilot trial of voice over Internet protocol-delivered behavior therapy for youth with chronic tic disorders. J Telemed Telecare 2016 Apr;22(3):153-162 [FREE Full text] [doi: 10.1177/1357633X15593192] [Medline: 26169350]

39. Bowen DJ, Kreuter M, Spring B, Cofta-Woerpel L, Linnan L, Weiner D, et al. How we design feasibility studies. Am J Prev Med 2009 May;36(5):452-457 [FREE Full text] [doi: 10.1016/j.amepre.2009.02.002] [Medline: 19362699]

40. Whaibeh E, Mahmoud H, Naal H. Telemental Health in the Context of a Pandemic: the COVID-19 Experience. Curr Treat Options Psychiatry 2020 Apr 02;7(2):1-5 [FREE Full text] [doi: 10.1007/s40501-020-00210-2] [Medline: 32292687]

41. Mallow JA, Petitte T, Narsavage G, Barnes E, Theeke E, Mallow BK, et al. The Use of Video Conferencing for Persons with Chronic Conditions: A Systematic Review. Ehealth Telecommun Syst Netw 2016 Jun;5(2):39-56 [FREE Full text] [doi: 10.4236/etsn.2016.52005] [Medline: 29104830]

42. Langarizadeh M, Tabatabaei M, Tavakol K, Naghipour M, Rostami A, Moghbeli F. Telemental Health Care, an Effective Alternative to Conventional Mental Care: a Systematic Review. Acta Inform Med 2017 Dec;25(4):240-246 [FREE Full text] [doi: $\underline{10.5455 / \text { aim.2017.25.240-246] [Medline: 29284913] }}$

Edited by J Torous, G Eysenbach; submitted 30.04.21; peer-reviewed by A Wickersham, C Son; comments to author 20.05.21; revised
version received 23.06.21; accepted 06.07.21; published 27.08.21
Please cite as:
Lau N, Colt SF, Waldbaum S, O'Daffer A, Fladeboe K, Yi-Frazier JP, McCauley E, Rosenberg AR
Telemental Health For Youth With Chronic Illnesses: Systematic Review
JMIR Ment Health 2021;8(8):e30098
URL: $\underline{\text { https://mental.jmir.org/2021/8/e30098 }}$
doi: $\underline{10.2196 / 30098}$
PMID: $\underline{34448724}$

CNancy Lau, Susannah F Colt, Shayna Waldbaum, Alison O'Daffer, Kaitlyn Fladeboe, Joyce P Yi-Frazier, Elizabeth McCauley, Abby R Rosenberg. Originally published in JMIR Mental Health (https://mental.jmir.org), 27.08.2021. This is an open-access article distributed under the terms of the Creative Commons Attribution License (https://creativecommons.org/licenses/by/4.0/), which permits unrestricted use, distribution, and reproduction in any medium, provided the original work, first published in JMIR Mental Health, is properly cited. The complete bibliographic information, a link to the original publication on https://mental.jmir.org/, as well as this copyright and license information must be included. 